\title{
Pivotal Roles of Ginsenoside Rg3 in Tumor Apoptosis Through Regulation of Reactive Oxygen Species
}

\author{
HWA YEON SUN ${ }^{1}$, JUN HEE LEE ${ }^{2}$, YONG-SEOK HAN ${ }^{1}$, YEO MIN YOON ${ }^{1}$, \\ CHUL WON YUN ${ }^{1}$, JAE HEON KIM ${ }^{3}$, YUN SEOB SONG ${ }^{3}$ and SANG HUN LEE ${ }^{1,4}$ \\ ${ }^{1}$ Medical Science Research Institute, Soonchunhyang University Seoul Hospital, Seoul, Republic of Korea; \\ ${ }^{2}$ Neuroregeneration and Stem Cell Programs, Institute for Cell Engineering, Department of Neurology, \\ The Johns Hopkins University School of Medicine, Baltimore, MD, U.S.A.; \\ ${ }^{3}$ Department of Urology, Soonchunhyang University School of Medicine, Seoul, Republic of Korea; \\ ${ }^{4}$ Department of Biochemistry, Soonchunhyang University College of Medicine, Cheonan, Republic of Korea
}

\begin{abstract}
Background: Elevated production of reactive oxygen species (ROS) is observed in various cancer types and pathophysiological conditions. In cancer cells, ROS induce cell proliferation, genetic instability, and a malignant phenotype. Ginsenoside Rg3 is the main pharmacologically active component in ginseng and has been reported to have an antioxidant effect. To overcome lung cancer by regulating the ROS level, we investigated the antitumor effect and mechanism of $\mathrm{Rg} 3$ and its antioxidative property on Lewis lung carcinoma (LLC) cells. Materials and Methods: Inhibition of ROS was suppressed in LLC cells by Rg3 treatment, and these cells were used to investigate the antioxidant, antiproliferative, and antitumor effects in LLC cells. Results: ROS production was increased in cells grown in serum-containing media (conditioned media) compared to those grown in serum-free media. The high level of ROS induced LLC cell proliferation, but treatment with $\mathrm{Rg} 3$ $(200 \mathrm{ng} / \mathrm{ml})$ resulted in reduction of $\mathrm{ROS}$, leading to inhibition of cell proliferation. Treatment with $\mathrm{Rg} 3$ significantly reduced cyclin and cyclin-dependent kinase expression in LLC cells. Additionally, Rg3 treatment significantly suppressed activation of mitogen-activated protein kinases and induced LLC cell apoptosis through activation of pro-apoptotic proteins and suppression of antiapoptotic proteins. Conclusion: Taken together, these findings demonstrate the role of $\mathrm{Rg} 3$ in reduction of the
\end{abstract}

Correspondence to: Sang Hun Lee, Soonchunhyang Medical Science Research Institute, Soonchunhyang University, Soonchunhyang Univ. Seoul Hospital, 59, Daesagwan-ro (657 Hannam-dong), Yongsan-gu, Seoul, 140-887, Republic of Korea. Tel: +82-2-709-9029, e-mail: ykckss1114@nate.com

Key Words: Ginsenoside $\operatorname{Rg} 3$, Lewis lung carcinoma, reactive oxygen species, anti-tumor effect, apoptosis. intracellular ROS level, attenuation of proliferation via augmentation of cell cycle-and cell proliferation-associated proteins, and activation of apoptosis through regulation of apoptosis-associated proteins in LLC. These findings suggest that Rg3 could be used as a therapeutic agent in lung cancer.

Lung cancer is the most common malignancy of the respiratory system, accounting for $23 \%$ of all malignant cancer deaths (1). After diagnosis, the survival rate in patients with lung cancer is approximately $15 \%$ at 5 years (2). Conventional therapy for lung cancer generally includes surgery, chemotherapy, and radiotherapy but results in a low survival rate because of their toxic side-effects $(3,4)$. Therefore, it is important to improve the therapeutic efficacy of lung cancer treatment and to reduce the associated sideeffects. In addition, novel anticancer agents are urgently needed. Several researchers have focused on natural products as cancer therapeutic agents with anti-aging, antiinflammatory, and antitumor effects (5-8).

Ginsenoside $\operatorname{Rg} 3$, the major active component of ginseng, has shown various pharmacological activities including immunomodulatory, antioxidant, anti-inflammatory, anticancer, and anti-aging activities in several diseases and infections, including different types of cancer, metabolic diseases, and neurodegenerative diseases (9, 10). Several studies show that Rg3 exhibits anticancer activities, such as inhibition of cancer cell growth, invasion and metastasis; suppression of angiogenesis; and induction of apoptosis, in different types of cancer, including ovarian, lung, intestinal, prostatic, and gastric (11-17). In addition, Rg3 reduces tumor migration and metastasis by inhibiting epithelialmesenchymal transition, which is an important factor in cancer metastasis (18).

Reactive oxygen species (ROS) are associated with cancer progression. ROS can both accelerate and delay tumor initiation and progression. ROS and oxidative stress result in 
cancer cell growth and genetic instability but a high level of ROS causes considerable damage, leading to cancer cell death (19). In addition, up-regulation of antioxidant capacity against intrinsic oxidative stress can confer drug resistance in cancer cells (20). Therefore, redox-regulatory pathways and signaling mechanisms should be investigated in more detail. Recently, Chandel and Tuveson proposed two potential antioxidant therapeutic strategies (21). The first involves effective therapies that can directly inhibit the generation of or scavenge ROS. The second strategy involves the inhibition of antioxidant systems, inducing tumor cell death because of toxicity due to the consequently high level of ROS. However, this strategy should be able to differentiate clearly between normal and cancer cells.

In this study, we investigated the effect of ginsenoside $\mathrm{Rg} 3$, as an antioxidant, on tumor apoptosis of Lewis lung carcinoma (LLC) cells. In addition, we explored the mechanism underlying the effects of $\operatorname{Rg} 3$ on tumor growth and apoptosis.

\section{Materials and Methods}

Preparation of ginsenoside Rg3. Ginsenoside $\mathrm{Rg} 3$ was purchased from Sigma Aldrich (St. Louis, MO, USA). Rg3 was dissolved in dimethyl sulfoxide, sterilized by filtration through a $0.45-\mu \mathrm{m}$ pore filter (Millipore, Billerica, MA, USA), and stored at $4^{\circ} \mathrm{C}$ until use.

Cell culture. Mouse LLC cells were kindly provided by the College of Pharmacy, Research Institute of Pharmaceutical Sciences, Kyungpook National University (Republic of Korea). The cells were maintained in Dulbecco's modified Eagle's medium (4.5 g/l glucose) supplemented with $10 \%$ fetal calf serum, L-glutamine, and antibiotics (Biological Industries, BeitHaemek, Israel) at $37^{\circ} \mathrm{C}$ with $5 \% \mathrm{CO}_{2}$ in a humidified incubator.

Cell viability assay. Exponentially growing LLC cells in 96-well plates $\left(1,000\right.$ cells/well) at subconfluence were incubated with $\mathrm{H}_{2} \mathrm{O}_{2}$ $\left(0-10^{-14} \mathrm{M}\right)$ for $24 \mathrm{~h}$ and different durations $(0,6,12$ and $24 \mathrm{~h})$ in serum-free medium, and treated with $\operatorname{Rg} 3(0,100,200,400$, and $600 \mathrm{ng} / \mathrm{ml})$ for different durations $(0,12,24$, and $48 \mathrm{~h})$ in conditioned medium. Cell viability was assessed using a modified 3-(4,5-dimethylthiazol-2-yl)-2,5-diphenyltetrazolium bromide (MTT) assay, based on the conversion of the tetrazolium salt 3-(4,5dimethylthiazol-2-yl)-5-(3-carbox ymethoxy phenyl)-2-(4sulfophenyl)-2-tetrazolium to formazan by mitochondrial dehydrogenase. The formazan product was quantified by evaluating the absorbance of the reaction at $570 \mathrm{~nm}$ by using the SPECTROstar Nano ${ }^{\circledR}$ (BMG Labtech, Ortenberg, Germany)

Western blot analysis. The proteins of LLC cells treated with $\operatorname{Rg} 3$ (200 $\mathrm{ng} / \mathrm{ml}$ ) were extracted using RIPA lysis buffer (Thermo Scientific, Rockford, IL, USA). The cell lysates were separated through sodium dodecyl sulfate-polyacrylamide gel electrophoresis and were transferred onto polyvinylidene fluoride membranes (Millipore). The membranes were blocked with $5 \%$ skim milk for $1 \mathrm{~h}$ at room temperature and then incubated overnight with primary antibodies at $4^{\circ} \mathrm{C}$. Antibodies against B-cell lymphoma 2 (BCL2), BCL2-associated
$\mathrm{X}$ protein (BAX), cleaved poly(ADP ribose)polymerase-1 (PARP1), cyclin-dependent kinase 2 (CDK2), CDK4, cyclin D1, cyclin E, extracellular signal-regulated kinase (ERK), p38, c-JUN $N$-terminal kinase (JNK), and $\beta$-actin (Santa Cruz Biotechnology, Dallas, TX, USA); and cleaved caspase-3 (Cell Signaling Technology, Danvers, MA, USA) were diluted in Tris-buffered saline in $0.2 \%$ Tween-20 (TBS-T). After the membranes were washed with TBS-T, the bound primary antibodies were detected using horseradish peroxidaseconjugated goat anti-rabbit IgG or goat anti-mouse IgG secondary antibodies (Santa Cruz Biotechnology). The bands were visualized using enhanced chemiluminescence reagents (Thermo Scientific, Rockford, IL, USA) in a dark room.

Flow cytometric analysis for ROS generation, proliferation, and apoptosis. LLC cells treated with $\mathrm{H}_{2} \mathrm{O}_{2}$ or $\mathrm{Rg} 3$ were harvested, fixed in $70 \%$ ethanol at $-20^{\circ} \mathrm{C}$ for $48 \mathrm{~h}$, and then washed twice with cold PBS. To detect ROS production, dihydroethidium (DHE, $10 \mu \mathrm{M}$; Sigma Aldrich) was added to the cells and the cells were then washed thrice with PBS. The cells were then incubated with RNase and the DNA-intercalating dye, propidium iodide (PI) for cell-cycle analysis or with PI and annexin V (SysmexPartec GmbH, Gorlitz, Germany) for apoptosis analysis. ROS generation, cell-cycle distribution, and apoptosis were assessed with a Cyflow Cube 8 instrument (Partec, Munster, Germany). Data analysis was performed using the standard FSC Express (De Novo Software, Los Angeles, CA, USA).

Statistical analyses. Results are expressed as mean \pm standard error of the mean (SEM). All experiments were analyzed by Student's $t$-test, where differences with $p<0.05$ were considered significant.

\section{Results}

Effect of ROS on proliferation of LLC cells. To investigate the difference between serum-free and conditioned media for ROS generation, ROS generation was confirmed by flow cytometry for DHE staining in cells from serum-free and conditioned media. ROS production was augmented in cells from conditioned medium compared to those in serum-free medium (Figure 1A). To explore whether ROS induced proliferation of LLC cells, the proliferative potential of LLC cells was assessed by flow cytometry for PI staining and by the MTT assay. Flow cytometry for PI staining indicated that conditioned medium-induced ROS generation resulted in a higher proliferative potential of LLC cells than did serumfree medium (Figure 1B). After treatment with $\mathrm{H}_{2} \mathrm{O}_{2}(0$ $\left.10^{-14} \mathrm{M}\right)$ to verify the association between ROS and LLC cells, cell proliferation assay was performed. The proliferation of LLC cells was significantly increased at a low concentration of $\mathrm{H}_{2} \mathrm{O}_{2}\left(10^{-10} \mathrm{M}\right)$ compared with that in the control cells (Figure 1C). In addition, the proliferation of LLC cells was significantly increased in a time-dependent manner (0-24 h; Figure 1D). These results show that ROS induce proliferation of LLC cells.

Ginsenoside Rg3 reduces LLC cell viability. To explore whether Rg3, as an antioxidant, reduces LLC cell viability, 
A

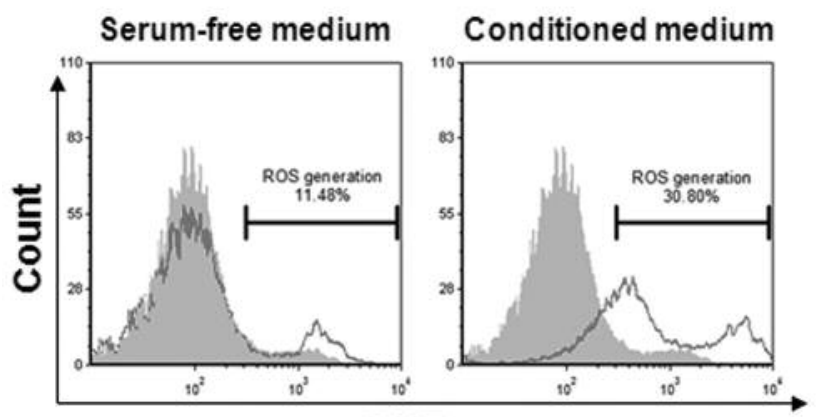

DHE

C

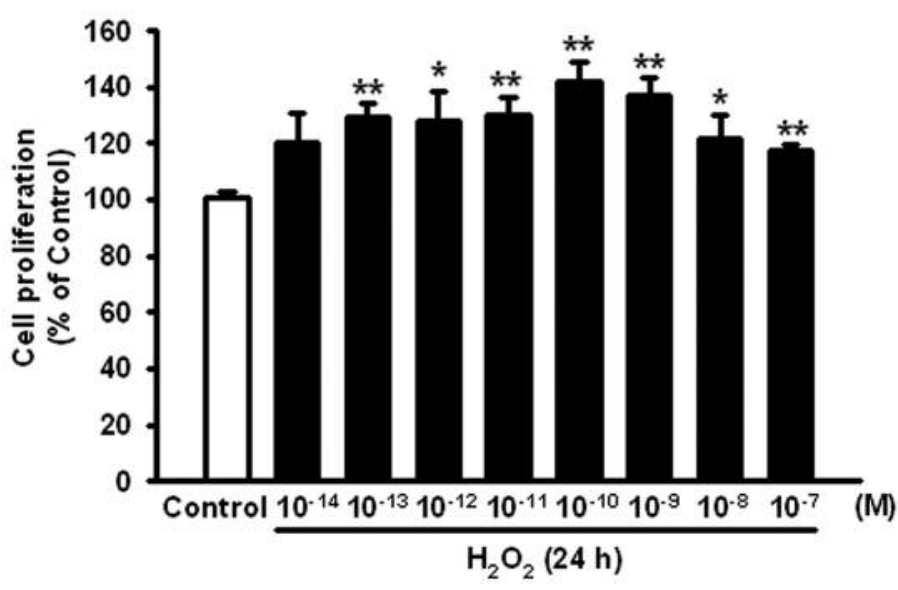

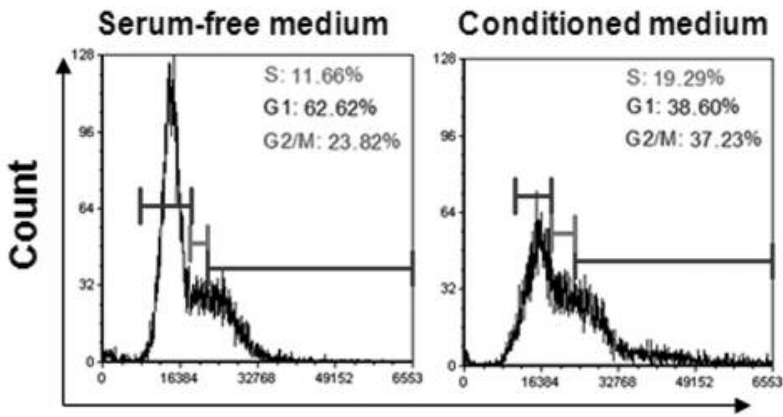

PI

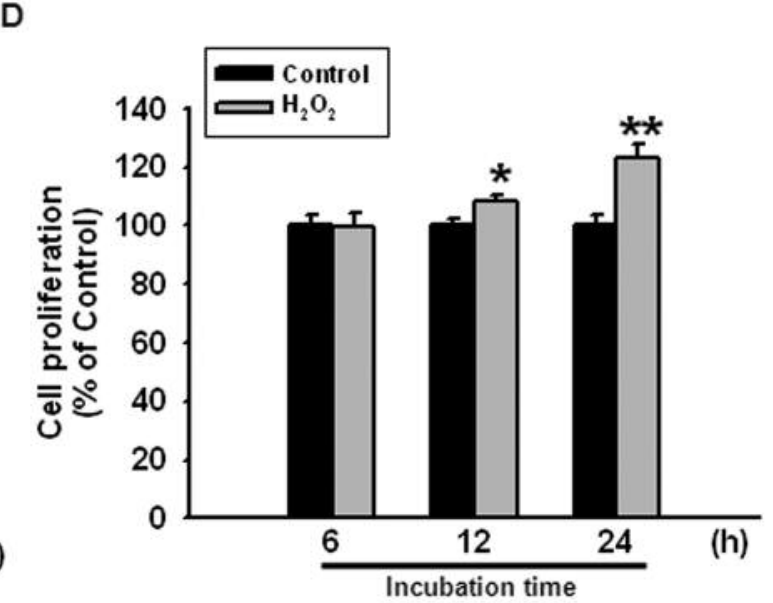

Figure 1. The effect of reactive oxygen species (ROS) on proliferation of Lewis lung carcinoma (LLC) cells. A: Production of ROS was assessed by flow cytometry for dihydroethidium (DHE) staining in serum-free and serum-containing (conditioned) media. B: Cells in the $S$ phase were measured using flow cytometry for propidium iodide (PI) staining in serum-free and conditioned media. C: Proliferation of LLC cells was evaluated after treatment with $\mathrm{H}_{2} \mathrm{O}_{2}$ for $24 \mathrm{~h}$. D: Proliferation of LLC cells was assessed after treatment with $\mathrm{H}_{2} \mathrm{O}_{2}\left(10^{-10} \mathrm{M}\right)$ for the indicated times.

an MTT assay was performed after treatment with $\operatorname{Rg} 3$ at different concentrations $(0-600 \mathrm{ng} / \mathrm{ml})$ for $48 \mathrm{~h}$. Cell viability was significantly lower at an $\operatorname{Rg} 3$ concentration of $200 \mathrm{ng} / \mathrm{ml}$ compared to that of the control (Figure 2A). Moreover, cell viability was significantly lower after treatment for $24 \mathrm{~h}$ and $48 \mathrm{~h}$ (Figure 2B). The number of LLC cells was significantly reduced when they were treated with $\mathrm{Rg} 3(200 \mathrm{ng} / \mathrm{ml})$ compared to control (Figure $2 \mathrm{C}$ ). To confirm the antioxidant effect of Rg3 in LLC cells, ROS generation was assessed by flow cytometry for DHE staining after treatment of LLC cells with $\operatorname{Rg} 3$. ROS production by LLC cells was found to be reduced by treatment with $\mathrm{Rg} 3$ in conditioned medium (Figure 2D). These findings indicate that $\mathrm{Rg} 3$ reduces LLC cell viability via reduction of the ROS level.

The mechanism underlying Rg3-mediated reduction of proliferation in $L L C$ cells. To verify whether $\mathrm{Rg} 3$ regulates cell proliferation-associated signaling pathways, these pathways in LLC cells were assessed by western blotting. On culture with conditioned medium, the percentage of LLC cells in the S phase decreased upon treatment with $\mathrm{Rg} 3(200 \mathrm{ng} / \mathrm{ml})$ compared to that of control (Figure 3A). The expression of cell cycle-associated proteins CDK2, cyclin E, CDK 4 and cyclin D1 significantly decreased in LLC cells treated with Rg3 compared with untreated cells (Figure 3B and C). In addition, the activation of cell proliferation-associated mitogen-activated protein kinases (MAPKs), ERK, p38, and JNK, was significantly reduced in LLC cells treated with $\mathrm{Rg} 3$ compared to untreated cells (Figure 4). Our findings suggest that Rg3 reduces LLC cell proliferation through regulation of cell cycleassociated proteins and phosphorylation of MAPKs.

Rg3 induces LLC cell apoptosis through activation of apoptosis-associated proteins. To investigate whether treatment 

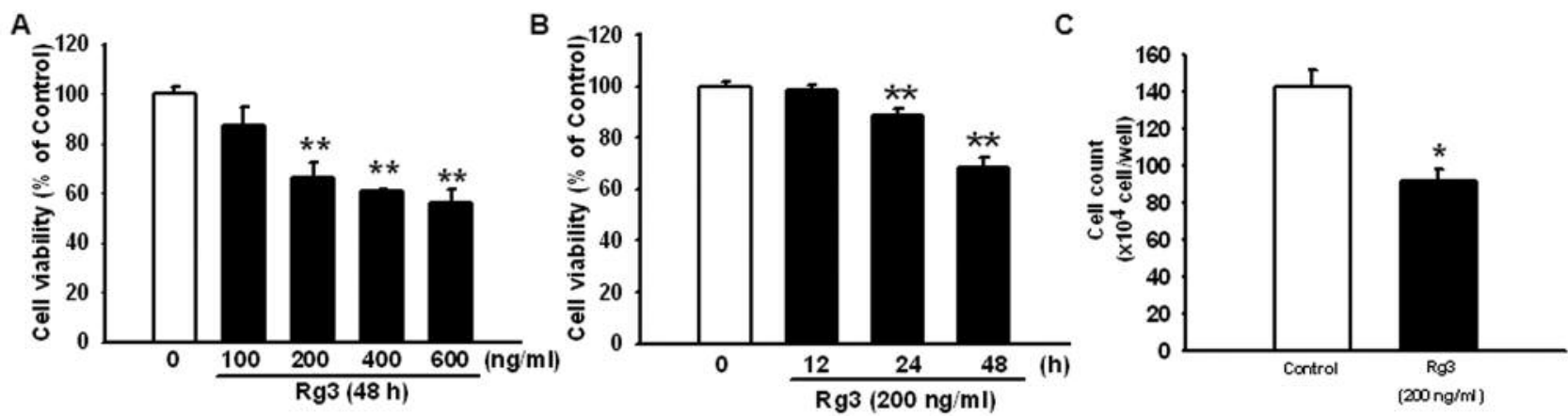

D

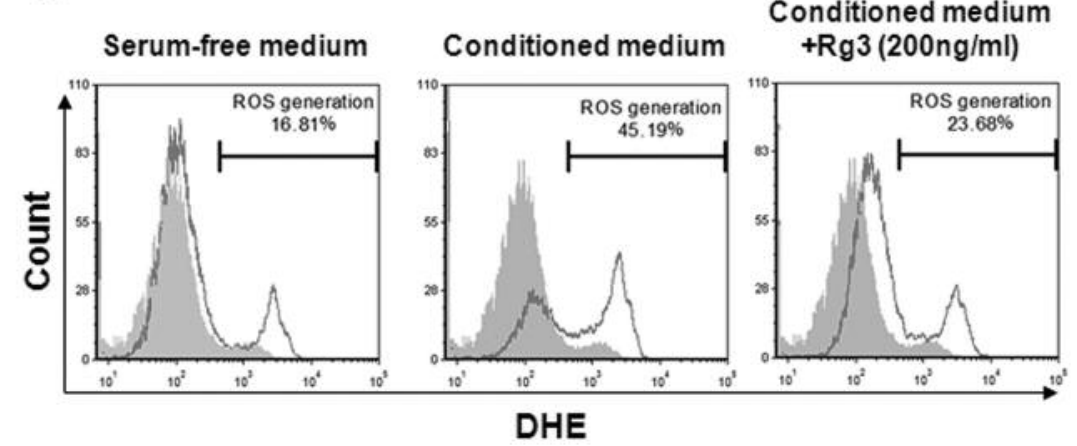

Figure 2. The effect of ginsenoside Rg3 on proliferation of Lewis lung cancer (LLC) cells. Cell viability was assessed after treatment with Rg3 at different concentrations for $48 \mathrm{~h}(\mathrm{~A})$ and after treatment with $\mathrm{Rg} 3(200 \mathrm{ng} / \mathrm{ml})$ for the indicated times $(\mathrm{B})$. C: After treatment with Rg3 (200 $\mathrm{ng} / \mathrm{ml})$ for $48 \mathrm{~h}$, the number of cells was directly counted. D: Reactive oxygen species (ROS) generation was evaluated using flow cytometry for dihydroethidium (DHE) staining. Values are expressed as the mean \pm SEM. $* p<0.05$ and $* * p<0.01 \mathrm{vs}$. control.

with $\operatorname{Rg} 3(200 \mathrm{ng} / \mathrm{ml})$ leads to LLC cell apoptosis, flow cytometry for PI and annexin V double staining was performed to assess the apoptotic cell population. The apoptotic cell population was found to be significantly higher upon treatment with $\operatorname{Rg} 3$ than in the control (Figure 5A). Apoptosis-associated proteins were assessed by western blotting. The expression of the anti-apoptotic protein BCL2 significantly decreased in Rg3treated cells compared to the control (Figure 5B). The expression of pro-apoptotic proteins BAX, PARP, and cleaved caspase-3 was significantly increased upon treatment with $\mathrm{Rg} 3$ compared to the control (Figure 5C-E). These results suggest that $\mathrm{Rg} 3$ promotes LLC cell apoptosis via the regulation of apoptosis-associated proteins.

\section{Discussion}

ROS, which act as secondary messengers in cellular signaling, play important roles in several normal physiological and abnormal pathophysiological processes. The ROS level is increased in various cancer cells because they have higher metabolic rates compared to normal cells (22). The high level of ROS generation in cancer cells result in stimulation of proliferation, promotion of mutations, induction of genetic instability, and enhancement of drug resistance (23), indicating that regulation of ROS metabolism and pathways in cancer cells might be an effective strategy for overcoming various types of cancer (24). This study demonstrated that Rg3, as a natural antioxidant, suppressed proliferation and induced apoptosis of LLC cells through the reduction of the ROS level. Moreover, these anticancer effects also involved regulation of cell proliferation- and apoptosis-associated proteins.

Ginsenosides have antioxidant, anti-inflammatory, and antitumor properties (25). Ginsenoside $\mathrm{Rg} 3$, one of the most active ginsenosides, has been shown to exhibit anticancer properties through its anti-angiogenesis (26) and anti-metastasis (27) effects, activation of endoplasmic reticulum stress (28), promotion of senescence and apoptosis (29), suppression of epithelial-mesenchymal transition (18), inhibition of proliferation (17), and attenuation of migration (30). In particular, Rg3 has antioxidant activities (31). Alphalipoic acid, another natural ROS scavenger, was shown to increase cellcycle arrest and apoptosis of breast cancer cells (32). The 


\section{A}

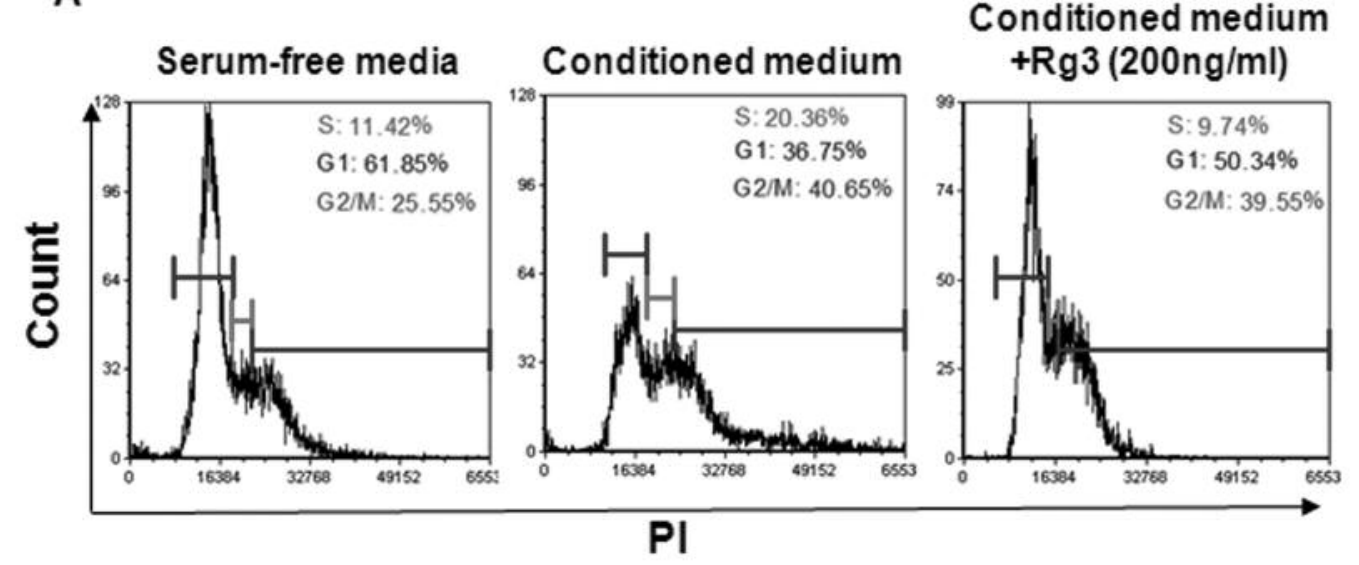

B
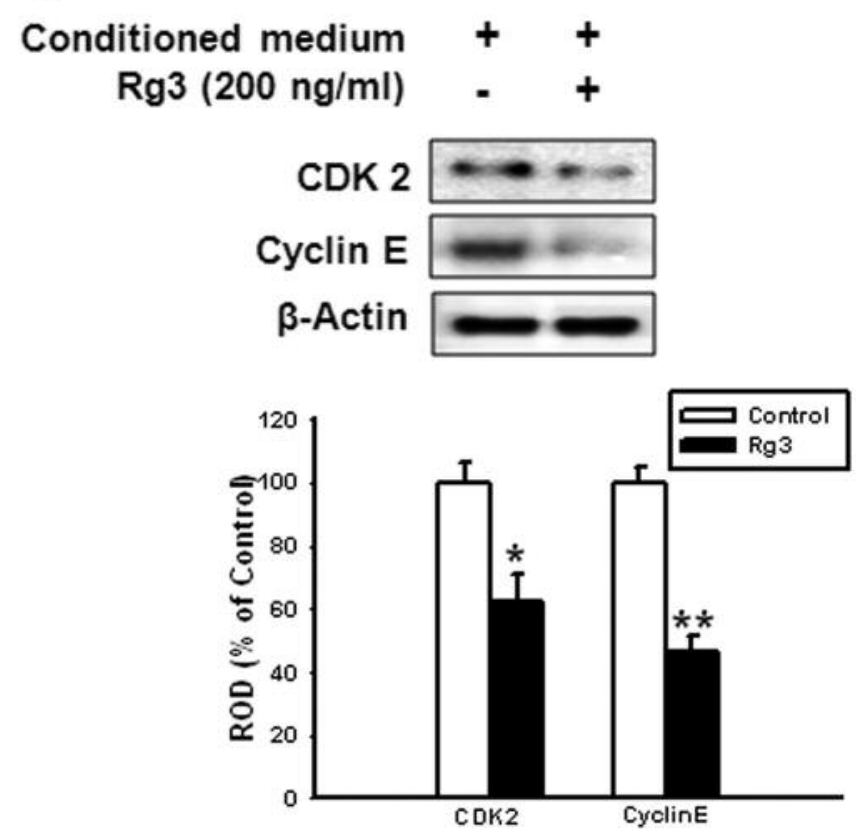

C
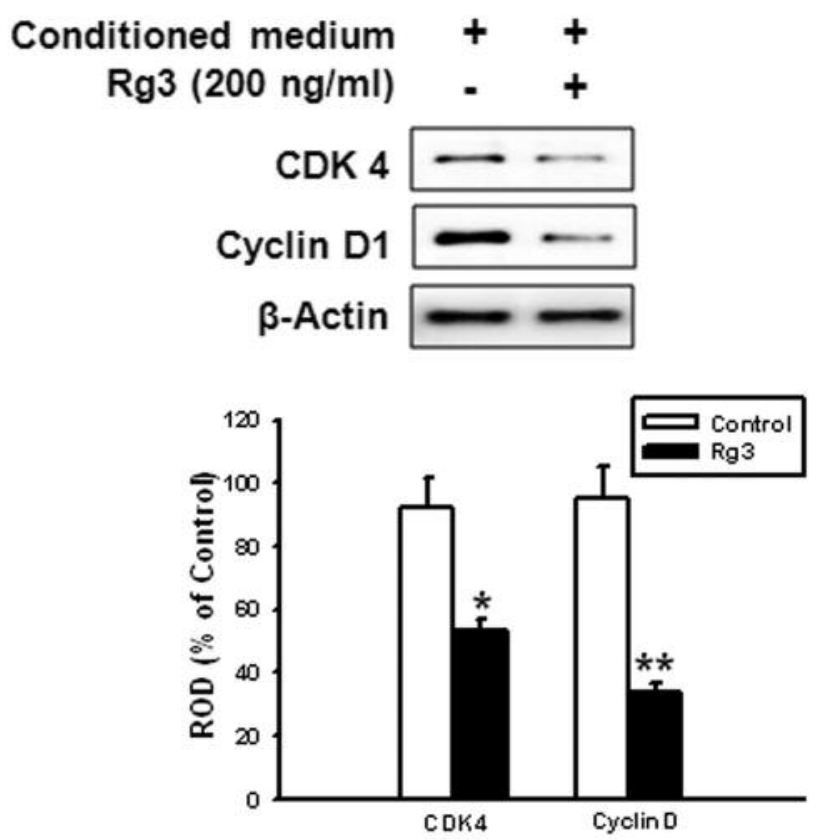

Figure 3. Rg3 reduces Lewis lung cancer $(L L C)$ cell proliferation through reduction of cell cycle-associated proteins. A: After treatment with Rg3 $(200 \mathrm{ng} / \mathrm{ml})$, cells in the $S$ phase were assessed by flow cytometry for propidium iodide (PI) staining. After treatment with Rg3 in conditioned medium, the expression of cyclin-dependent kinase 2 (CDK2), cyclin E (C), CDK4 and cyclin D1 (D) was assessed by western blotting. The lower panel shows the expression levels of proteins normalized to that of $\beta$-actin. Values represent the mean $\pm S E M .{ }^{*} p<0.05$ and $* * p<0.01 \mathrm{vs}$. untreated LLC cells.

apolipoprotein A1 mimetic peptide suppressed proliferation and tumorigenicity of epithelial ovarian cancer cells via induction of the antioxidant enzyme manganese-dependent superoxide dismutase (33). In this study, ROS generation was significantly increased in cells from conditioned medium compared to those cultured in serum-free medium, resulting in ROS-mediated promotion of LLC cell proliferation. In addition, we reveal that treatment with $\operatorname{Rg} 3$ reduced ROS production, thereby reducing
LLC cell viability. Our findings suggest that $\operatorname{Rg} 3$ inhibits LLC cell viability via its antioxidant effect.

ROS-regulated signal pathways include pro-survival and pro-proliferative pathways, including ERK, JNK, and p38 MAPKs (34). Our results indicate that treatment with $\mathrm{Rg} 3$ inhibited LLC cell proliferation through suppression of cell cycle-associated proteins, including CDK2, cyclin E, CDK4, and cyclin D1, and cell growth-associated MAPKs, 
A

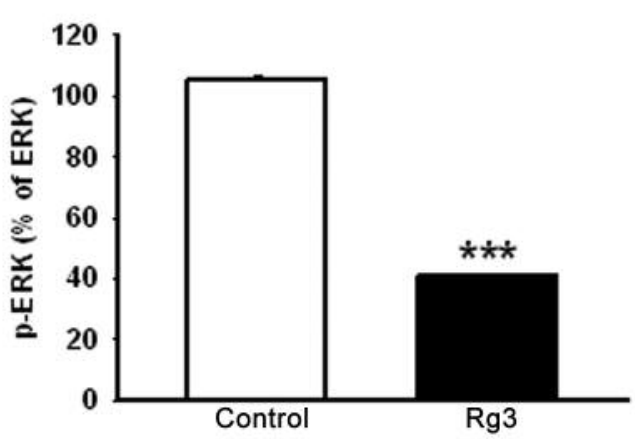

B
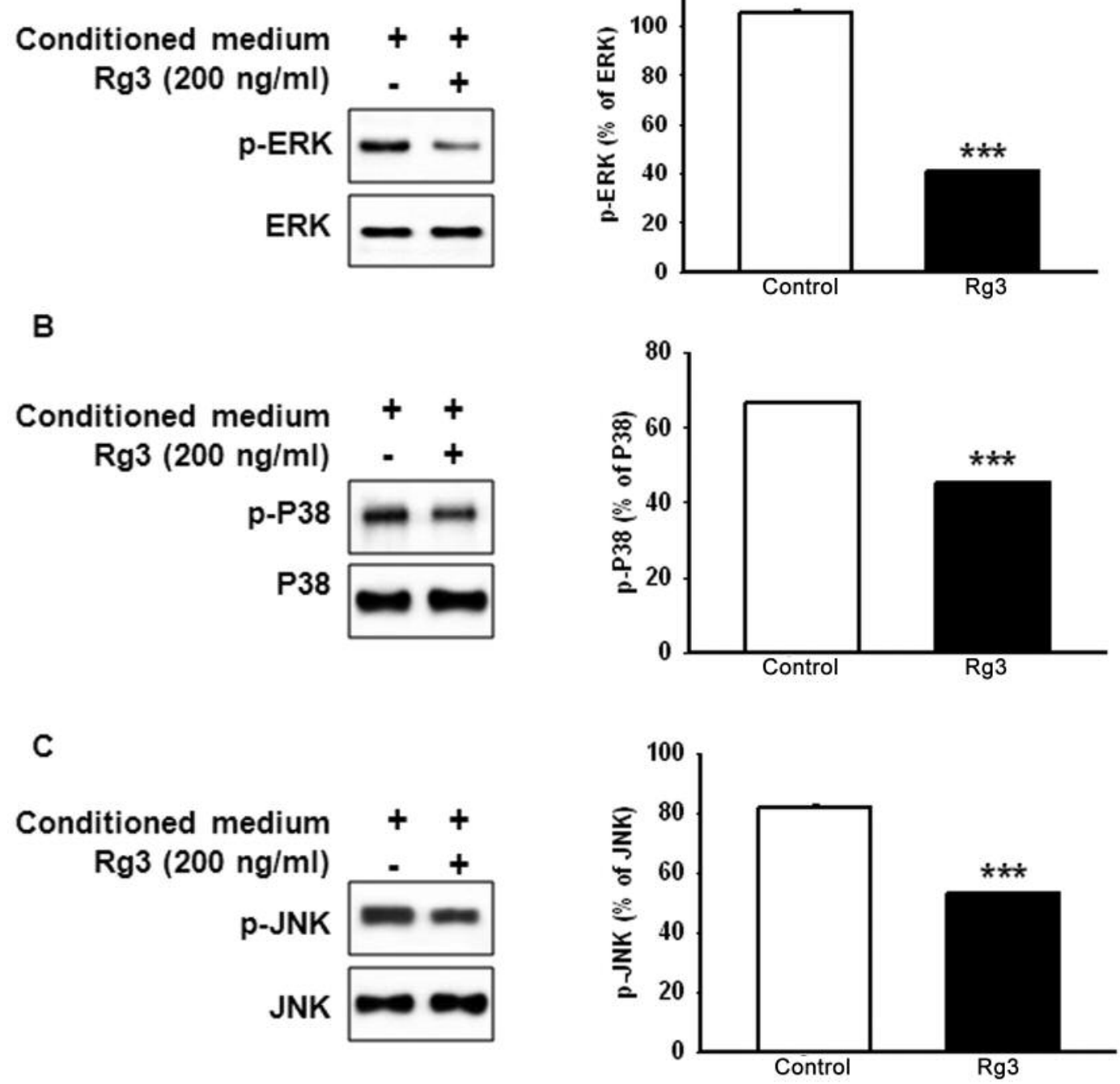

Figure 4. Rg3 reduces the activation of cell proliferation-associated mitogen-activated protein kinases (MAPK). After treatment of Lewis lung cancer (LLC) cells with Rg3 (200 ng/ml) for $48 \mathrm{~h}$ in conditioned medium, the phosphorylation of extracellular signal-regulated kinases (ERK) (A), p38 mitogen-activated protein kinases ( $p 38)(B)$, and c-JUN N-terminal kinases (JNK) (C) was assessed by western blot. The right panel shows the phosphorylation levels of ERK, p38, and JNK normalized to that of total ERK, p38, and JNK, respectively. Values represent the mean \pm SEM. $* * * p<0.001$ vs. untreated LLC cells.

including ERK, p38, and JNK. Rg3-induced MAPK deactivation was found to inhibit melanoma cell proliferation via reducing fucosyltransferase 4 expression (17). Moreover, our findings revealed that $\mathrm{Rg} 3$ induced LLC cell apoptosis via regulation of apoptosis-associated proteins, such as BCL2, BAX, PARP-1, and cleaved caspase-3. Rg3 was also found to induce human myeloma cell apoptosis by activating BAX and cleaved caspase-3 (35). Furthermore, $\mathrm{Rg} 3$ induced apoptosis of hepatoma cells through activation of the mitochondrial pathway (36). Taken together, these findings suggest that $\operatorname{Rg} 3$ suppresses cell proliferation and induces apoptosis of LLC cells through modulation of cell proliferation- and apoptosis-associated proteins.

In conclusion, this study demonstrates the anticancer effects of ginsenoside $\mathrm{Rg} 3$ through the regulation of ROS in LLC cells. Our data indicate that ROS were significantly reduced by the natural product $\mathrm{Rg} 3$, resulting in inhibition of LLC cell viability. In addition, our findings showed that $\operatorname{Rg} 3$ inhibited the expression of cancer cell proliferation-associated proteins and promoted activation of the apoptosis pathway, suggesting that $\operatorname{Rg} 3$ could be a potential chemopreventive agent for lung carcinoma. 
A

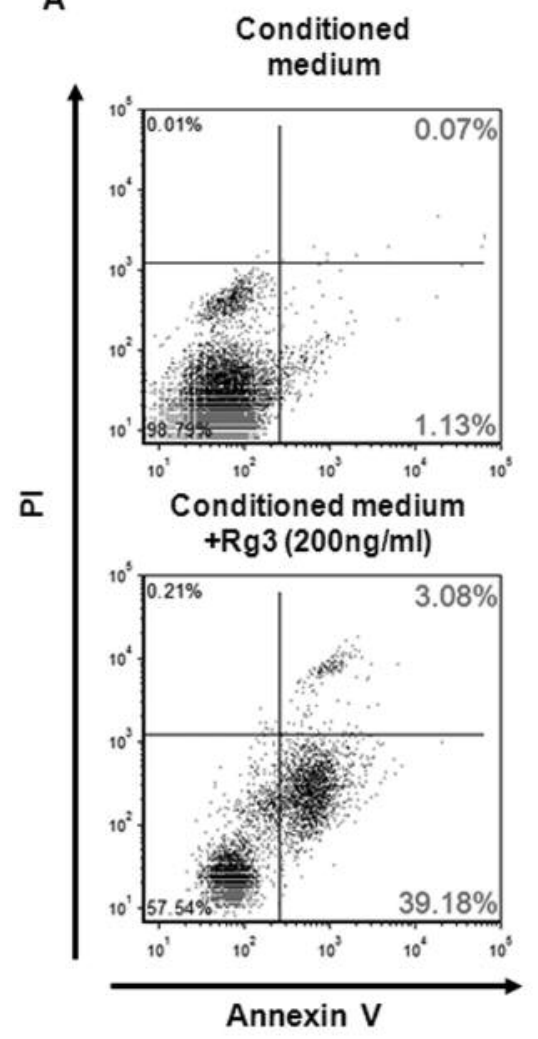

B

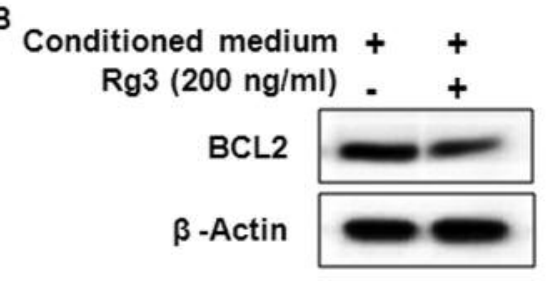

C

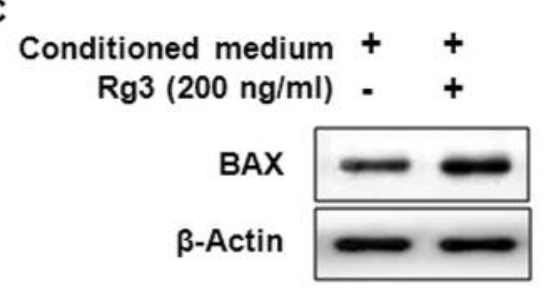

D

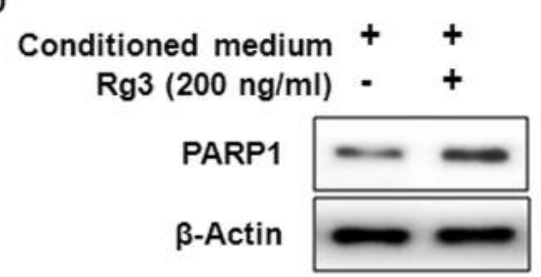

E

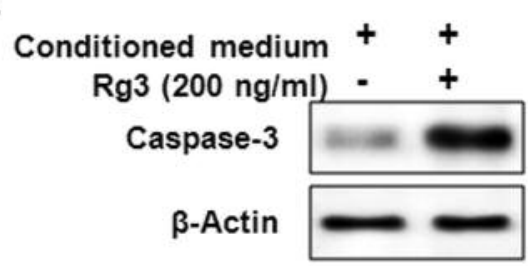

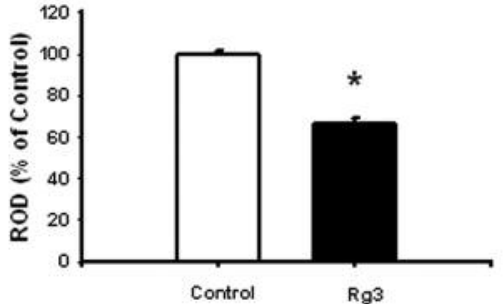
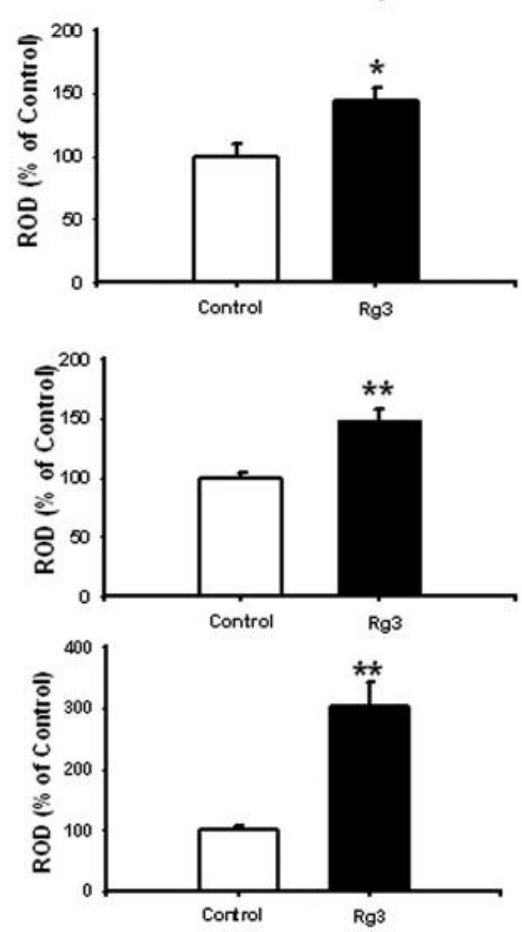

Figure 5. Rg3 induces Lewis lung cancer (LLC) cell apoptosis through regulation of apoptosis-associated proteins. A: LLC cell apoptosis was measured using flow cytometry for propidium iodide (PI)/annexin V double staining. PI/annexin V double-negative cells were considered as live cells, PI-negative/annexin V-positive cells were considered as early apoptotic cells, and PI/annexin V double-positive cells were considered late apoptotic cells. After treatment with Rg3 (200 $\mathrm{ng} / \mathrm{ml})$ for $48 \mathrm{~h}$ in conditioned medium, the expression of B-cell lymphoma 2 (BCL2) (B), BCL-2associated $X$ protein $(B A X)(C)$, cleaved poly [ADP-ribose] polymerase $1(P A R P 1)(D)$, and cleaved caspase-3 $(E)$ was assessed by western blotting. The right panel shows the expression levels of BCL2, BAX, cleaved PARP1, and cleaved caspase-3 normalized to that of $\beta$-actin. Values represent the mean \pm SEM. $* p<0.05$ and $* * p<0.01$ vs. untreated LLC cells.

\section{Acknowledgements}

This work was supported by the Soonchunhyang University Research Fund (20150664), a National Research Foundation grant funded by the Korean government (2016R1D1A3B01007727) Republic of Korea. a grant from the Korean Health Technology R\&D Project, Ministry of Health and Welfare, Republic of Korea (HI14C2253). The funders had no role in the study design, data collection or analysis, the decision to publish, or preparation of the article.

\section{Conflicts of Interest}

The Authors have no conflicts of interest to declare in regard to this study.

\section{References}

1 Jemal A, Bray F, Center MM, Ferlay J, Ward E and Forman D: Global cancer statistics. CA Cancer J Clin 61(2): 69-90, 2011.

2 Nag SA, Qin JJ, Wang W, Wang MH, Wang H and Zhang R: Ginsenosides as anticancer agents: In vitro and in vivo activities, structure-activity relationships, and molecular mechanisms of action. Front Pharmacol 3: 25, 2012.

3 Murray N and Turrisi AT, 3rd: A review of first-line treatment for small-cell lung cancer. J Thorac Oncol 1(3): 270-278, 2006.

4 Hann CL and Rudin CM: Management of small-cell lung cancer: Incremental changes but hope for the future. Oncology 22(13): 1486-1492, 2008. 
5 Christensen LP: Ginsenosides chemistry, biosynthesis, analysis, and potential health effects. Adv Food Nutr Res 55: 1-99, 2009.

6 De Smet PA: Herbal remedies. N Engl J Med 347(25): 20462056, 2002.

7 Joo EJ, Chun J, Ha YW, Ko HJ, Xu MY and Kim YS: Novel roles of ginsenoside $\mathrm{Rg} 3$ in apoptosis through downregulation of epidermal growth factor receptor. Chem Biol Interact 233: 2534, 2015.

8 Wang DD, Feng Y, Li Z, Zhang L, Wang S, Zhang CY, Wang $\mathrm{XX}$ and Liu ZY: In vitro and in vivo antitumor activity of bulbus Fritillariae cirrhosae and preliminary investigation of its mechanism. Nutr Cancer 66(3): 441-452, 2014.

9 Lim TG, Lee CC, Dong Z and Lee KW: Ginsenosides and their metabolites: A review of their pharmacological activities in the skin. Arch Dermatol Res 307(5): 397-403, 2015.

$10 \mathrm{Xu}$ FY, Shang WQ, Yu JJ, Sun Q, Li MQ and Sun JS: The antitumor activity study of ginsenosides and metabolites in lung cancer cell. Am J Transl Res 8(4): 1708-1718, 2016.

11 Iishi H, Tatsuta M, Baba M, Uehara H, Nakaizumi A, Shinkai $\mathrm{K}$, Akedo H, Funai H, Ishiguro S and Kitagawa I: Inhibition by ginsenoside $\operatorname{Rg} 3$ of bombesin-enhanced peritoneal metastasis of intestinal adenocarcinomas induced by azoxymethane in wistar rats. Clin Exp Metastasis 15(6): 603-611, 1997.

$12 \mathrm{Xu}$ TM, Xin Y, Cui MH, Jiang X and Gu LP: Inhibitory effect of ginsenoside $\operatorname{Rg} 3$ combined with cyclophosphamide on growth and angiogenesis of ovarian cancer. Chin Med J (Engl) 120(7): 584-588, 2007.

13 Chen J, Peng H, Ou-Yang X and He X: Research on the antitumor effect of ginsenoside $\mathrm{Rg} 3$ in b16 melanoma cells. Melanoma Res 18(5): 322-329, 2008.

14 Kim BJ, Nah SY, Jeon JH, So I and Kim SJ: Transient receptor potential melastatin 7 channels are involved in ginsenoside Rg3induced apoptosis in gastric cancer cells. Basic Clin Pharmacol Toxicol 109(4): 233-239, 2011.

15 Kim JW, Jung SY, Kwon YH, Lee JH, Lee YM, Lee BY and Kwon SM: Ginsenoside Rg3 attenuates tumor angiogenesis via inhibiting bioactivities of endothelial progenitor cells. Cancer Biol Ther 13(7): 504-515, 2012.

16 Kim JW, Jung SY, Kwon YH, Lee SH, Lee JH, Lee BY and Kwon SM: Ginsenoside Rg3 inhibits endothelial progenitor cell differentiation through attenuation of vegf-dependent akt/enos signaling. Phytother Res 26(9): 1286-1293, 2012.

17 Shan X, Aziz F, Tian LL, Wang XQ, Yan Q and Liu JW: Ginsenoside $\operatorname{Rg} 3$-induced egfr/mapk pathway deactivation inhibits melanoma cell proliferation by decreasing fut4/ley expression. Int J Oncol 46(4): 1667-1676, 2015.

18 Tian L, Shen D, Li X, Shan X, Wang X, Yan Q and Liu J: Ginsenoside $\operatorname{Rg} 3$ inhibits epithelial-mesenchymal transition (emt) and invasion of lung cancer by down-regulating fut 4 . Oncotarget 7(2): 1619-1632, 2016.

19 Schumacker PT: Reactive oxygen species in cancer cells: Live by the sword, die by the sword. Cancer Cell 10(3): 175-176, 2006.

20 Trachootham D, Alexandre J and Huang P: Targeting cancer cells by ros-mediated mechanisms: A radical therapeutic approach? Nat Rev Drug Discov 8(7): 579-591, 2009.

21 Chandel NS and Tuveson DA: The promise and perils of antioxidants for cancer patients. N Engl J Med 371(2): 177-178, 2014.

22 Ambrosone CB: Oxidants and antioxidants in breast cancer. Antioxid Redox Signal 2(4): 903-917, 2000.
23 Pelicano H, Carney D and Huang P: Ros stress in cancer cells and therapeutic implications. Drug Resist Updat 7(2): 97-110, 2004.

24 Ding S, Li C, Cheng N, Cui X, Xu X and Zhou G: Redox regulation in cancer stem cells. Oxid Med Cell Longev 2015: 750798, 2015.

25 Lee $\mathrm{CH}$ and Kim JH: A review on the medicinal potentials of ginseng and ginsenosides on cardiovascular diseases. J Ginseng Res 38(3): 161-166, 2014.

26 Sun C, Yu Y, Wang L, Wu B, Xia L, Feng F, Ling Z and Wang $\mathrm{S}$ : Additive antiangiogenesis effect of ginsenoside $\mathrm{Rg} 3$ with lowdose metronomic temozolomide on rat glioma cells both in vivo and in vitro. J Exp Clin Cancer Res 35: 32, 2016.

27 Lee SG, Kang YJ and Nam JO: Anti-metastasis effects of ginsenoside Rg3 in b16f10 cells. J Microbiol Biotechnol 25(12): 1997-2006, 2015.

$28 \mathrm{Wu} \mathrm{K}$, Li N, Sun H, Xu T, Jin F and Nie J: Endoplasmic reticulum stress activation mediates ginseng $\mathrm{Rg} 3$-induced antigallbladder cancer cell activity. Biochem Biophys Res Commun 466(3): 369-375, 2015.

29 Zhang F, Li M, Wu X, Hu Y, Cao Y, Wang X, Xiang S, Li H, Jiang L, Tan Z, Lu W, Weng H, Shu Y, Gong W, Wang X, Zhang Y, Shi W, Dong P, Gu J and Liu Y: 20(s)-ginsenoside Rg3 promotes senescence and apoptosis in gallbladder cancer cells via the p53 pathway. Drug Des Devel Ther 9: 3969-3987, 2015.

30 Pan XY, Guo H, Han J, Hao F, An Y, Xu Y, Xiaokaiti Y, Pan Y and $\mathrm{Li} \mathrm{XJ}$ : Ginsenoside $\mathrm{Rg} 3$ attenuates cell migration via inhibition of aquaporin 1 expression in pc-3m prostate cancer cells. Eur J Pharmacol 683(1-3): 27-34, 2012.

31 Wei X, Su F, Su X, Hu T and Hu S: Stereospecific antioxidant effects of ginsenoside $\operatorname{Rg} 3$ on oxidative stress induced by cyclophosphamide in mice. Fitoterapia 83(4): 636-642, 2012.

32 Dozio E, Ruscica M, Passafaro L, Dogliotti G, Steffani L, Marthyn P, Pagani A, Demartini G, Esposti D, Fraschini F and Magni P: The natural antioxidant alpha-lipoic acid induces p27(kip1)-dependent cell cycle arrest and apoptosis in mcf-7 human breast cancer cells. Eur J Pharmacol 641(1): 29-34, 2010.

33 Ganapathy E, Su F, Meriwether D, Devarajan A, Grijalva V, Gao F, Chattopadhyay A, Anantharamaiah GM, Navab M, Fogelman AM, Reddy ST and Farias-Eisner R: D-4f, an apoa-i mimetic peptide, inhibits proliferation and tumorigenicity of epithelial ovarian cancer cells by upregulating the antioxidant enzyme mnsod. Int J Cancer 130(5): 1071-1081, 2012.

34 Weinberg F and Chandel NS: Reactive oxygen speciesdependent signaling regulates cancer. Cell Mol Life Sci 66(23): 3663-3673, 2009.

35 Luo Y, Zhang P, Zeng HQ, Lou SF and Wang DX: Ginsenoside $\mathrm{Rg} 3$ induces apoptosis in human multiple myeloma cells via the activation of bcl-2-associated x protein. Mol Med Rep 12(3): 3557-3562, 2015.

36 Park HM, Kim SJ, Kim JS and Kang HS: Reactive oxygen species mediated ginsenoside Rg3- and rh2-induced apoptosis in hepatoma cells through mitochondrial signaling pathways. Food Chem Toxicol 50(8): 2736-2741, 2012.

Received July 22, 2016

Revised August 4, 2016

Accepted August 5, 2016 